\title{
Bone marrow-derived mesenchymal stromal cell: what next?
}

This article was published in the following Dove Press journal: Stem Cells and Cloning:Advances and Applications

\author{
Fernanda T Borges ${ }^{1,2}$ \\ Marcia Bastos Convento' \\ Nestor Schor ${ }^{1, \dagger}$ \\ 'Nephrology Division, Department \\ of Medicine, Universidade Federal \\ de São Paulo, São Paulo, SP, Brazil; \\ Interdisciplinary Postgraduate \\ Program in Health Sciences, \\ Universidade Cruzeiro do Sul, São \\ Paulo, SP, Brazil \\ †Professor Nestor Schor passed away \\ on February 2, 2018
}

Correspondence: Fernanda T Borges Interdisciplinary Postgraduate Program in Health Sciences, Universidade Cruzeiro do Sul, Rua Galvão Bueno 868, Liberdade, São Paulo, SP, CEP 01506-000, Brazil Tel +55 II 3003 I I89 Email ft.borges@unifesp.br

\begin{abstract}
Bone marrow mesenchymal stromal cell (MSC) is a potential alternative in regenerative medicine and has great potential in many pathologic conditions including kidney disease. Although most of the studies demonstrate MSC efficiency, the regenerative potential may not be efficient in all diseases and patients. Stem cell feasibility is modified by donor characteristics as gender, age, diet, and health status, producing both positive and negative results. The conditioning of MSC can potentiate its effects and modify its culture medium (CM). In current practices, the cell-free treatment is gaining notable attention, while MSCconditioned CM is being applied and studied in many experimental diseases, including, but not limited to, certain kidney diseases. This may be the next step for clinical trials. Studies in stem cell CM have focused mainly on extracellular vesicles, nucleic acids (mRNA and microRNA), lipids, and proteins presented in this CM. They mediate regenerative effects of MSC in a harmonic manner. In this review, we will analyze the regenerative potential of MSC and its CM as well as discuss some effective techniques for modifying its fractions and improving its therapeutic potential. CM fractions may be modified by hypoxic conditions, inflammation, lipid exposition, and protein growth factors. Other possible mechanisms of action of stem cells are also suggested. In the future, the MSC paracrine effect may be modified to more closely meet each patient's needs.
\end{abstract}

Keywords: mesenchymal stromal cells, secretome, extracellular vesicles, microRNAs, lipids, growth factor

\section{Introduction}

Stem cell therapy is a potential alternative for many pathological conditions, including kidney diseases.

Stem cell is characterized by maintaining unlimited self-renewing ability, remaining indefinitely undifferentiated, and possessing the capacity to differentiate and transform into cells with a specific phenotype. ${ }^{1}$

Stem cells differ according to their differentiation capabilities. Pluripotent stem cells, including embryonic stem cells (ESC) and induced pluripotent stem cells (iPSC), differentiate in almost all mammalian cell lineages. Multipotent or adult stem cells have limited differentiation capacities, are present in specific niches in mammalian organs, and are sources of cell renewal. ${ }^{2}$

In mammals, progenitor mesenchymal cells participate in the glomerular and tubule development, but in adult kidneys, progenitor population disappears. Nevertheless, some studies suggest the presence of these progenitor cells in adult kidneys ${ }^{3-5}$ and 
employ progenitor cells to treat experimental models of kidney diseases. ${ }^{6-8}$

The number of studies mentioning stem cells increases each year. A search on PubMed during the first semester of 2018 coupled with the term "stem cell" found almost 23,000 articles. One of the cells most frequently studied is the mesenchymal stem cell or mesenchymal stromal cell (MSC). ${ }^{9}$

Initially obtained from bone marrow (BM-MSC), MSCs are multipotent stem cells that present positive surface markers like CD90, CD105, and CD73 and negative surface markers such as CD45, CD34, CD14, CD79 $\alpha$, CD11b, CD19, or Human Leukocyte Antigen-DR isotype molecules. ${ }^{10}$

Additionally, they transformed into mesoderm-derived cell types including adipocytes, chondrocytes, and osteocytes. ${ }^{11}$ Nevertheless, similar cells were obtained from almost all adult tissues and organs when introduced in culture conditions including peripheral blood, liver, spleen, placenta, umbilical cord, and amniotic membrane. ${ }^{9}$

BM-MSC was the first stem cell well-characterized, ${ }^{12-14}$ and the MSC most often studied either in vitro or in vivo. Its protective and regenerative potential was demonstrated not only in experimental models of acute kidney injury induced by cisplatin, ${ }^{15}$ gentamicin, ${ }^{16}$ ischemia, and reperfusion ${ }^{17}$ but also in chronic kidney disease. ${ }^{18,19}$

One frequently investigated aspect of MSC is its mechanism of action. Initially, three hypotheses were suggested: first was the homing to the injury site and fusion with the resident cell, second was the transdifferentiation into the resident cell and repopulation of injured tissue, and third was the paracrine effect. ${ }^{20}$ Currently, the most widely accepted hypothesis is the paracrine effect, at least in regard to kidney diseases. To prove the final hypothesis, studies used the culture medium (CM) of stem cells to reproduce their regenerative effect on pathological conditions. ${ }^{21,22}$

The advantage of using the $\mathrm{CM}$ is the lower risk of immunogenicity or tumorigenicity. The ability to induce teratoma was notably demonstrated by the use of pluripotent stem cells including iPSCs ${ }^{23}$ and ESCs. ${ }^{24}$ Initially, it was reported that no tumor was detected after the transplant of human or animal MSCs, ${ }^{25}$ suggesting MSC was not tumorigenic. Nevertheless, other studies reported malignant lesions that have the capability of transforming into tumors even after the transplant of MSC has occurred. ${ }^{26,27}$ Cell-free therapy reinforces the concept that the MSC-CM is a safe option for the use of the cell.

$\mathrm{MSC}$, in naive conditions, expresses intermediate major histocompatibility complex class I molecules as opposed to class II molecules. These molecules are not recognized by alloreactive T-cells, showing low level of immunogenicity. Additionally, BM-MSC have potent immunosuppressive effects, which corroborate the low immunogenicity. ${ }^{28} \mathrm{Nev}-$ ertheless, it is noteworthy to emphasize that most studies regarding BM-MSC analyzed their protective/regenerative effects only for a few days or weeks, and consequently suggest that stem cells were washed out from the site after 24 hours or if they were trapped in the lungs. ${ }^{29}$ Manuscripts focusing on the immunogenicity or tumorigenicity of BMMSC for long periods after transplant occurred were not conducted extensively and are still necessary in current practice.

\section{The MSC-CM and its modification}

The CM of MSC or its secretome is composed mainly of lipids, proteins, and nucleic acid-enriched extracellular vesicles (EVs). Each fraction of CM has been analyzed by its regenerative and/or protective properties, but the secretome most likely works in a harmonic way and not in an independent manner.

Despite this behavior, it is reasonable to suggest that the regenerative potential of MSC secretome (EVs, lipids, and proteins) can be modified by its microenvironment under pathological conditions. MSC can be conditioned by the microenvironment in constant changes to adjust the secretome to its external conditions. This feature may be used to improve, potentiate, or adjust the paracrine effect of MSC according to each patient's condition.

The MSC secretome and its constituents will be analyzed in the following sections.

\section{EVs in MSC secretome}

EVs are micro- or nanoparticles produced and released from all living cells in an organism; EV carry (messenger RNA) mRNA, microRNA, and proteins to mediate intercellular communication. They include mainly microvesicles, exosomes, and apoptotic bodies. ${ }^{30}$

Exosomes are 50-150 $\mathrm{nm}$ diameter nanoparticles produced intracellularly in the multivesicular bodies (MVB). They present characteristic proteins like the tetraspanin family members (CD63, CD81, and CD9), heat-shock proteins, ${ }^{31}$ and endosomes such as Alix and TSG101. ${ }^{32}$ Exosomes are released in answer to the microenvironment modifications after primary endosome formation. MVB membrane fuses with the plasmatic membrane, releasing exosomes into the environment where they can be overtaken by other cells in order to mediate a paracrine communication. Microvesicles are $100-1,000 \mathrm{~nm}$ diameter particles sprouting from the plasmatic membrane, which also carry mRNA, microRNA, and proteins from the cytoplasm. ${ }^{30}$ 
EVs are present in practically all biological fluids, and urine exosomes are potential biomarkers for kidney diseases. ${ }^{30}$

The therapeutic potential of MSC microvesicles and exosomes was demonstrated in many kidney diseases, such as gentamicin nephrotoxicity, ${ }^{16}$ cisplatin nephrotoxicity, ${ }^{33-35}$ ischemia/reperfusion, ${ }^{36}$ and acute kidney injury to chronic kidney disease transition. ${ }^{37}$ The resulting therapeutic effect is related to their cargo, which includes microRNA, mRNA, and proteins; our understanding of EV cargo, however, is still incomplete.

EV obtained from MSC and potentially other various cell types represent a heterogeneous population varying in density, surface markers, protein, and microRNA cargo and biological activity of kidney cells. ${ }^{38} \mathrm{~A}$ recent study demonstrates that EV obtained from MSC-CM were initially separated into 12 fractions according to gradient density techniques; they were posteriorly grouped into three fractions of low, medium, and high density according to markers and density.

The low- and medium-density fractions showed diameter between 50 and $150 \mathrm{~nm}$ when compared to the high-density fraction, presenting an EV greater in diameter $(>200 \mathrm{~nm})$. The medium-density fraction showed CD63 and CD81 markings - HLA-I and $\alpha_{5}$-integrin - which suggests an exosome-enriched population. This fraction showed proliferation activity on tubular epithelial cells under culture conditions and an antiapoptotic effect on tubular cells exposed to hypoxia. Low- and high-density fractions demonstrated in a lesser extension the surface marking CD63, HLA-I, and $\alpha_{5}$-integrin, which suggests a microvesicle-enriched fraction. These results did not show antiapoptotic proprieties on proximal tubular cells under hypoxic conditions.

MicroRNAs carried by EV from the medium-density fraction were associated with stem cell effects in processes such as inflammation, migration, and metabolism. Protein cargo from EV in a medium-density fraction was composed of signaling molecules, receptors, and cell adhesion proteins involved in a regenerative/protective process. ${ }^{38}$

These results suggest that EV obtained from an MSC-CM showed different populations that included exosomes and microvesicles with different cargo and properties considerable for potentiating an EV therapeutic effect.

As mentioned above, MSC-derived EV amount and cargo can be modified by microenvironmental conditions. ${ }^{39,40}$ Hypoxia is a potent stimulant of EV production and modulates its cargo to increase angiogenesis. ${ }^{41,42}$ These features could potentially have beneficial therapeutic effects.

\section{Lipids in MSC secretome}

MSC-CM lipidic fraction is studied much less frequently than EV and proteins. Most studies analyze the therapeutic potential for MSC in culture conditions enriched with fatty acids. Omega-3 unsaturated fatty acids (docosahexaenoic and eicosapentaenoic acids) generate mediators during inflammation and/or resolution of inflammation called lipid mediators. These mediators include resolvins, neuroprotectin/protectins, and maresins that may be responsible for the beneficial effects provided by these unsaturated fatty acids. ${ }^{43,44}$ Resolvins, protectins, and maresins stimulate inflammation resolution through cessation of leukocyte infiltration, counterregulation of proinflammatory mediators, and the uptake of apoptotic neutrophils and cellular debris. ${ }^{45}$

Docosahexaenoic acid (DHA) is an essential omega-3 fatty acid that generates lipid mediators in MSC. The exposition of murine MSC to a lipid mediator (14S,21R-diHDHA) for 12 hours improved the renoprotective effect of MSC in an ischemia/reperfusion model of acute kidney injury. The exposition increased the antiapoptotic, anti-inflammatory effects of MSC, inhibiting leukocyte infiltration and inflammatory cytokine generation. ${ }^{46}$

This strategy, aimed toward conditioning MSC, was also utilized in other practices. Human MSC was cultured for 7 days in the presence of linoleic and oleic acids (omega- 6 and omega-9 unsaturated fatty acids, respectively). ${ }^{47}$ Both reduced MSC viability but increased migration, which may have influenced the cellular homing to the site of the injury. Also, unsaturated fatty acid increased angiogenesis mediators vascular endothelial growth factor (VEGF), IL-1 $\beta$, IL-8, and nitric oxide, ${ }^{47}$ this result was also observed with DHA. ${ }^{48} \mathrm{Nev}-$ ertheless, the explanation as to how omega- 6 and omega- 9 affect MSC is still to be determined, but there is a compelling suggestion stating that fatty acid conditioning of MSC may improve some of its properties.

It was demonstrated that MSC loses some properties, like multipotency, and undergoes senescence during long culture conditions. ${ }^{49}$ During prolonged culture conditions, there is a decrease in omega- 6 fatty acids with decreases in membrane fluidity. To counterbalance this, the cell decreases saturated fatty acid and increases monounsaturated fatty acids in plasmatic membrane; plasmatic membrane does not produce the same bioactive products, which interferes with cellular plasticity as indicated by cellular differentiation. Moreover, the supplementation of lipids restores some of these properties like cell differentiation, trafficking, protein synthesis, and folding. ${ }^{50}$

These results suggest that MSC can be conditioned through lipid supplementation or lipid mediators to improve 
or restore some of its ability. Therefore, it is reasonable to infer that a cell affected by senescence or prolonged culture conditions or a cell obtained from a patient in pathological conditions can be restored or improved for autologous transplant.

We suggest that the same can occur with the MSC paracrine effect. Therefore, lipid exposition can improve or restore the MSC paracrine effect, and the practice can certainly be explored in regenerative strategies.

\section{Proteins in MSC secretome}

MSCs produce and secrete protein growth factors that mediate its paracrine effect, as has already been demonstrated. ${ }^{51-53}$ Some of these paracrine factors include hepatocyte growth factor (HGF), insulin-like growth factor (IGF), VEGF, etc. ${ }^{51}$ They are involved in antifibrotic, angiogenic, and antiapoptotic effects of MSC. . $^{52,53}$

MSC can be conditioned to produce protein growth factors and improve its proprieties. Hypoxia can improve antifibrotic effects of MSC through HGF production. ${ }^{54-56}$

Other protein factors include erythropoietin ${ }^{57}$ and granulocyte colony-stimulating factor $(\mathrm{G}-\mathrm{CSF})^{56}$ that are capable of improving some proprieties of MSC such as differentiation, migration to the injury site, and regenerative capacity.

Another potent stimulus is inflammation. Conditioning of MSC with tumor necrosis factor $\alpha$ (TNF- $\alpha$ ), an inflammatory cytokine produced by macrophages, stimulated an MSC angiogenic effect through VEGF production, proliferation, and differentiation into osteocytes. ${ }^{58,59}$

Proteins can also be carried by EVs released by MSC, which keep them protected from microenvironment proteases. These EVs can be endocyted by recipient cells and the proteins released into the cytoplasm can modify the cellular behavior. However, soluble proteins presented in $\mathrm{CM}$ stimulate recipient cells through membrane receptors, which activate intracellular machinery to promote cellular effect.

\section{Donor status affects MSC secretome}

MSC effects exhibit efficiency according to many factors already discussed. Additionally, the efficiency of MSC can be influenced by interpersonal variability such as donor age, health status, or even tissue origin. For example, donor health conditions and other characteristics influence MSC functions and feasibility, which has already been demonstrated by previous studies. ${ }^{60}$

Literature still lacks the necessary breadth of information regarding how diet supplementation or physical activity could affect MSC characteristics, like proliferation capacity, self- renewal, and more. Additionally, can the protective effect of MSC be modulated or improved by diet or physical activity? The answer currently remains unknown.

\section{In vitro culture condition affects MSC secretome}

A concern regarding the near future is stem cell culture conditions. The MSC culture in 3D spheres is advantageous for producing cells in the secretome including EV, proteins, etc. Nevertheless, 3D culture conditions can also modify stem cell secretome, which influences its therapeutic potential and can also be used to improve it. ${ }^{61,62}$ The $3 \mathrm{D}$ culture and other cell culture conditions can influence the MSC therapeutic effect, and consequently should be more thoroughly explored.

\section{Other possible mechanism of action of stem cell: tunneling nanotubes (TNT)}

Recent studies suggest that MSC can either communicate with neighboring cells through TNT formation ${ }^{63}$ or MSC can stimulate the TNT in a paracrine formation to mediate communication between resident cells. ${ }^{64}$

Nanotubes were recently considered one mechanism of cellular communication that allows the transferring of cytoplasmic components such as prions, mitochondria, lysosome, ions, and bacterial pathogens between neighboring cells.

In umbilical cord MSC, nanotubes were characterized as cellular protrusions with 100-700 $\mu \mathrm{m}$ in distance and 50-200 $\mathrm{nm}$ in diameter. Two types of TNT were identified: thinner TNT and thicker TNT.

The thinner TNT measures no more than $100 \mathrm{~nm}$ in diameter and is formed by actin filaments; its function is transporting soluble cytoplasmic substances. The thicker TNT measures 600-700 $\mathrm{nm}$ in diameter and is formed by actin and tubulin filaments; its function is transporting vesicles, mitochondria, and cisterns of rough endoplasmic reticulum. ${ }^{65}$

TNT seems to be, at least partially, a mediator of MSC regenerative activity in the kidney. MSC induced TNT formation when cultured with tubular epithelial cells. These tubular cells transferred mitochondria between neighboring cells through nanotubes. ${ }^{64}$ This mitochondrial transfer conferred resistance of the tubular epithelial cell to cisplatin-induced injury and acute renal failure in mice. The work demonstrated that umbilical cord MSC stimulated SIRT3 function in tubular cells, deacetylated mitochondrial proteins, increased ATP production, and induced potent antioxidant effects. ${ }^{64}$

The TNT-mediated communication between MSC and resident cells is advantageous and could be explored to 
possibly improve MSC therapeutic potential. Nevertheless, additional studies are necessary in order to understand TNT structure and function for cellular therapy.

\section{MSC clinical trial conditions}

MSC is the main cell type present in clinical trials. However, placental, bone marrow, and fat-derived stromal cells have also been used, but the preference focuses on characteristics observed in animal studies; these characteristics include immunosuppressive and anti-inflammatory properties, homing capacity, and short-time existence when transplanted, which may directly influence safety. There seems to be no difference between allogenic and autologous transplants. In fact, this lack of discrepancy is considered an advantage since gender, age, pathologic conditions, etc, may affect MSC properties. ${ }^{60,66}$

Both ESC and iPSC are of great interest, especially with the difficulty obtaining adult stem cells for many tissues and organs; however, safety is still a great concern.

There are studies using differentiated ESC, a strategy for security issues, to treat pancreas, ${ }^{67}$ the eye,${ }^{68,69}$ and Parkinson's disease. ${ }^{70}$ Additionally, iPSC is not being applied to clinical studies because of regulatory approval. Clinical trial failures are still frequent, but these failures are fortunately not discouraging future trials because even more scientific knowledge is being accumulated.

In the beginning of 2018, 164 (2.48\%) of 6,600 clinical trials involved the study of stem cells or transplantation of stem cells for kidney diseases. ${ }^{71}$ Twenty-four trials had applied MSCs (14.6\%), and 41 had applied progenitor cells (25\%), among other types of stem cells. Half of all studies analyzing kidney diseases (54.9\%) were in kidney cancer patients (Figure 1).

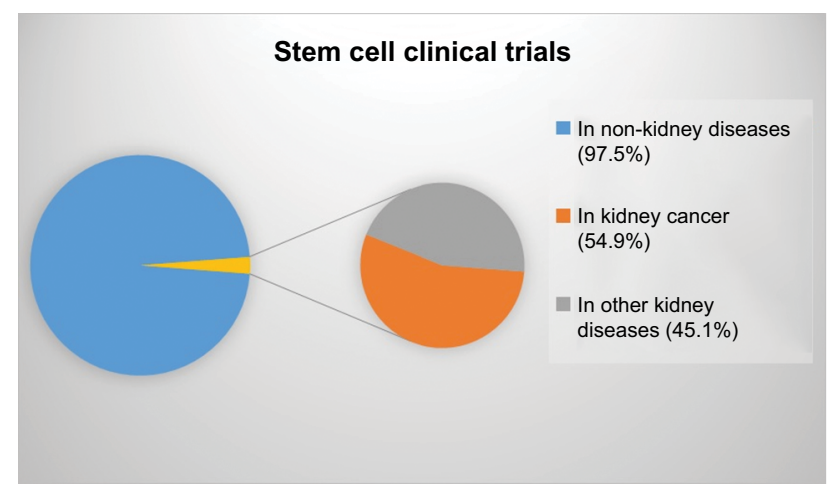

Figure I Proportion of clinical trials studying stem cells in non-kidney and kidney diseases, as well as kidney disease related to cancer.
Other stem cells like pluripotent-induced cells differentiated in that PSC or ESC stem cells should be more employed in the future by utilizing more than one cell in a combined treatment. Perhaps the next step in clinical trials will be preconditioning stem cells to improve the cell trait or ability or preconditioning the $\mathrm{CM}$ to individualize the treatment.

\section{Perspectives and future directions}

The transplant of MSC or its paracrine/endocrine factors is still promising nowadays. Despite this, the advantages of MSC paracrine factors can be minimized, abolished, or potentiated by the feasibility of stem cells according to donor characteristics (gender, age, etc) or by the conditioning of stem cells regarding inflammation or hypoxia, etc (Figure 2). Looking toward the future, we conclude that the next step could be the conditioning of stem cells.

It is difficult to believe that one or few stem cell lines are effective for all diseases and all types of patients, but this notion was our first impression after analyzing experimental studies using stem cells. Perhaps, in the future, cellular therapy will be based on the needs of the patient, individualizing the treatment through stem cell conditioning or choosing stem cell lines according to donor characteristics in order to potentiate the effects of cell therapy.

\section{Acknowledgment}

This work is dedicated to Prof Dr Nestor Schor, a researcher ahead of his time who contributed a lot to the development of science and research in nephrology in Brazil.

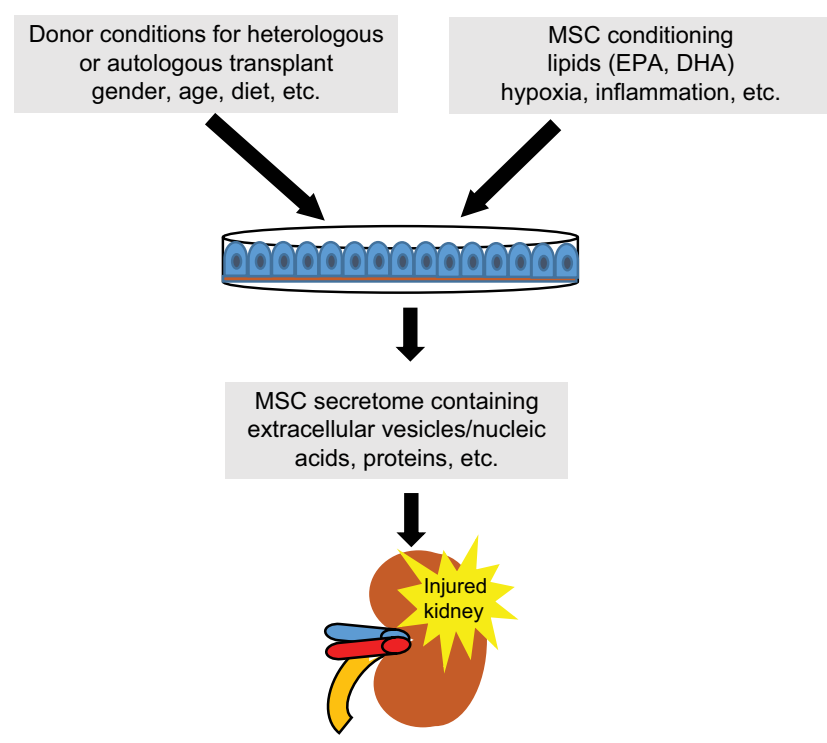

Figure 2 MSC conditioning with lipids, growth factor, or EVs or selection of donor conditions to obtain MSCs adequate for transplant patient.

Abbreviations: DHA, docosahexaenoic acid; EPA, eicosapentaenoic acid; EV, extracellular vesicle; MSC, mesenchymal stromal cell. 


\section{Disclosure}

The authors report no conflicts of interest in this work.

\section{References}

1. Williams N, Jackson H, Rabellino EM. Proliferation and differentiation of normal granulopoietic cells in continuous bone marrow cultures. $J$ Cell Physiol. 1977;93(3):435-439.

2. Barrilleaux B, Phinney DG, Prockop DJ, O’Connor KC. Review: ex vivo engineering of living tissues with adult stem cells. Tissue Eng. 2006;12(11):3007-3019.

3. Maeshima A, Yamashita S, Nojima Y. Identification of renal progenitorlike tubular cells that participate in the regeneration processes of the kidney. J Am Soc Nephrol. 2003;14(12):3138-3146.

4. Bussolati B, Bruno S, Grange C, et al. Isolation of renal progenitor cells from adult human kidney. Am J Pathol. 2005;166(2):545-555.

5. Fanni D, Fanos V, Gerosa C, et al. CD44 immunoreactivity in the developing human kidney: a marker of renal progenitor stem cells? Ren Fail. 2013;35(7):967-970.

6. Bussolati B, Camussi G. New Insights into the Renal Progenitor Cells and Kidney Diseases by Studying CD133. Adv Exp Med Biol. 2013;777:113-123.

7. Kinomura M, Kitamura S, Tanabe K, et al. Amelioration of cisplatininduced acute renal injury by renal progenitor-like cells derived from the adult rat kidney. Cell Transplant. 2008;17(1-2):143-158.

8. Ronconi E, Sagrinati C, Angelotti ML, et al. Regeneration of glomerular podocytes by human renal progenitors. J Am Soc Nephrol. 2009;20(2):322-332.

9. Murray IR. Péault B. Q\&A: Mesenchymal stem cells - where do they come from and is it important? BMC Biol. 2015;13:99.

10. Dominici M, Le Blanc K, Mueller I, et al. Minimal criteria for defining multipotent mesenchymal stromal cells. The International Society for Cellular Therapy position statement. Cytotherapy. 2006;8(4):315-317.

11. Yagi H, Soto-Gutierrez A, Kitagawa Y, Tilles AW, Tompkins RG, Yarmush ML. Bone marrow mesenchymal stromal cells attenuate organ injury induced by LPS and burn. Cell Transplant. 2010;19(6):823-830.

12. Friedenstein AJ, Piatetzky-Shapiro II, Petrakova KV. Osteogenesis in transplants of bone marrow cells. J Embryol Exp Morphol. 1966;16(3):381-390.

13. Friedenstein AJ, Chailakhyan RK, Latsinik NV, Panasyuk AF, KeilissBorok IV. Stromal cells responsible for transferring the microenvironment of the hemopoietic tissues. Cloning in vitro and retransplantation in vivo. Transplantation. 1974;17(4):331-340.

14. Friedenstein AJ. Stromal mechanisms of bone marrow: cloning in vitro and retransplantation in vivo. Haematol Blood Transfus. 1980;25:19-29.

15. Qi S, Wu D. Bone marrow-derived mesenchymal stem cells protect against cisplatin-induced acute kidney injury in rats by inhibiting cell apoptosis. Int J Mol Med. 2013;32(6):1262-1272.

16. Reis LA, Borges FT, Simões MJ, Borges AA, Sinigaglia-Coimbra R, Schor N. Bone marrow-derived mesenchymal stem cells repaired but did not prevent gentamicin-induced acute kidney injury through paracrine effects in rats. PLoS One. 2012;7(9):e44092.

17. Cantaluppi V, Gatti S, Medica D, et al. Microvesicles derived from endothelial progenitor cells protect the kidney from ischemia-reperfusion injury by microRNA-dependent reprogramming of resident renal cells. Kidney Int. 2012;82(4):412-427.

18. da Silva AF, Silva K, Reis LA, Teixeira VP, Schor N. Bone MarrowDerived Mesenchymal Stem Cells and Their Conditioned Medium Attenuate Fibrosis in an Irreversible Model of Unilateral Ureteral Obstruction. Cell Transplant. 2015;24(12):2657-2666.

19. Caldas HC, de Paula Couto TA, Fernandes IM, et al. Comparative effects of mesenchymal stem cell therapy in distinct stages of chronic renal failure. Clin Exp Nephrol. 2015;19(5):783-789.

20. Borges FT, Schor N. Regenerative medicine in kidney disease: where we stand and where to go. Pediatr Nephrol. 2018;33(9):1457-1465.

21. Golle L, Gerth HU, Beul K, et al. Bone marrow-derived cells and their conditioned medium induce microvascular repair in uremic rats by stimulation of endogenous repair mechanisms. Sci Rep. 2017;7(1):9444.
22. Iseri $\mathrm{K}$, Iyoda $\mathrm{M}$, Ohtaki $\mathrm{H}$, et al. Therapeutic effects and mechanism of conditioned media from human mesenchymal stem cells on antiGBM glomerulonephritis in WKY rats. Am J Physiol Renal Physiol. 2016;310(11):F1182-F1191.

23. Abad M, Mosteiro L, Pantoja C, et al. Reprogramming in vivo produces teratomas and iPS cells with totipotency features. Nature. 2013;502(7471):340-345.

24. Blum B, Benvenisty N. The tumorigenicity of human embryonic stem cells. Adv Cancer Res. 2008;100:133-158.

25. Barkholt L, Flory E, Jekerle V, et al. Risk of tumorigenicity in mesenchymal stromal cell-based therapies-bridging scientific observations and regulatory viewpoints. Cytotherapy. 2013;15(7):753-759.

26. Thirabanjasak D, Tantiwongse K, Thorner PS. Angiomyeloproliferative lesions following autologous stem cell therapy. J Am Soc Nephrol. 2010;21(7):1218-1222.

27. Houghton J, Stoicov C, Nomura S, et al. Gastric cancer originating from bone marrow-derived cells. Science. 2004;306(5701):1568-1571.

28. Le Blanc K, Tammik C, Rosendahl K, Zetterberg E, Ringdén O. HLA expression and immunologic properties of differentiated and undifferentiated mesenchymal stem cells. Exp Hematol. 2003;31(10):890-896.

29. Oliveira-Sales EB, Varela VA, Maquigussa E, et al. Renovascular hypertension: Effects of mesenchymal stem cells in the contralateral hypertensive kidney in rats. Clin Exp Hypertens. 2016;38(7):586-593.

30. Borges FT, Reis LA, Schor N. Extracellular vesicles: structure, function, and potential clinical uses in renal diseases. Braz J Med Biol Res. 2013;46(10):824-830.

31. Konala VB, Mamidi MK, Bhonde R, Das AK, Pochampally R, Pal R. The current landscape of the mesenchymal stromal cell secretome: A new paradigm for cell-free regeneration. Cytotherapy. 2016;18(1):13-24.

32. Chiasserini D, Mazzoni M, Bordi F, et al. Identification and Partial Characterization of Two Populations of Prostasomes by a Combination of Dynamic Light Scattering and Proteomic Analysis. J Membr Biol. 2015;248(6):991-1004.

33. Bruno S, Grange C, Collino F, et al. Microvesicles derived from mesenchymal stem cells enhance survival in a lethal model of acute kidney injury. PLoS One. 2012;7(3):e33115.

34. Wang B, Jia H, Zhang B, et al. Pre-incubation with hucMSC-exosomes prevents cisplatin-induced nephrotoxicity by activating autophagy. Stem Cell Res Ther. 2017;8(1):75.

35. Zhou Y, Xu H, Xu W, et al. Exosomes released by human umbilical cord mesenchymal stem cells protect against cisplatin-induced renal oxidative stress and apoptosis in vivo and in vitro. Stem Cell Res Ther. 2013;4(2):34.

36. Gatti S, Bruno S, Deregibus MC, et al. Microvesicles derived from human adult mesenchymal stem cells protect against ischaemiareperfusion-induced acute and chronic kidney injury. Nephrol Dial Transplant. 2011;26(5):1474-1483.

37. Zhu F, Chong Lee Shin OLS, Pei G, et al. Adipose-derived mesenchymal stem cells employed exosomes to attenuate AKI-CKD transition through tubular epithelial cell-dependent Sox 9 activation. Oncotarget. 2017;8(41):70707-70726.

38. Bruno S, Tapparo M, Collino F, et al. Renal Regenerative Potential of Different Extracellular Vesicle Populations Derived from Bone Marrow Mesenchymal Stromal Cells. Tissue Eng Part A. 2017;23(21-22):1262-1273.

39. Borges FT, Melo SA, Özdemir BC, et al. TGF- $\beta 1$-containing exosomes from injured epithelial cells activate fibroblasts to initiate tissue regenerative responses and fibrosis. JAm Soc Nephrol. 2013;24(3):385-392.

40. da Silva Novaes A, Ribeiro RS, Pereira LG, Borges FT, Boim MA. Intracrine action of angiotensin II in mesangial cells: subcellular distribution of angiotensin II receptor subtypes AT. Mol Cell Biochem. Epub 2018 Feb 17.

41. Han YD, Bai Y, Yan XL, et al. Co-transplantation of exosomes derived from hypoxia-preconditioned adipose mesenchymal stem cells promotes neovascularization and graft survival in fat grafting. Biochem Biophys Res Commun. 2018;497(1):305-312.

42. Li H, Liu D, Li C, et al. Exosomes secreted from mutant-HIF-1 modified bone-marrow-derived mesenchymal stem cells attenuate early steroid-induced avascular necrosis of femoral head in rabbit. Cell Biol Int. 2017;41(12):1379-1390. 
43. Duffield JS, Hong S, Vaidya VS, et al. Resolvin D series and protectin D1 mitigate acute kidney injury. J Immunol. 2006;177(9):5902-5911.

44. Serhan CN, Clish CB, Brannon J, Colgan SP, Chiang N, Gronert K. Novel functional sets of lipid-derived mediators with antiinflammatory actions generated from omega-3 fatty acids via cyclooxygenase 2-nonsteroidal antiinflammatory drugs and transcellular processing. $J$ Exp Med. 2000;192(8):1197-1204.

45. Serhan CN, Chiang N, Dalli J, Levy BD. Lipid mediators in the resolution of inflammation. Cold Spring Harb Perspect Biol. 2014;7(2): a016311.

46. Tian H, Lu Y, Shah SP, Wang Q, Hong S. 14S,21R-dihydroxydocosahexaenoic acid treatment enhances mesenchymal stem cell amelioration of renal ischemia/reperfusion injury. Stem Cells Dev. 2012;21(7):1187-1199.

47. Smith AN, Muffley LA, Bell AN, Numhom S, Hocking AM. Unsaturated fatty acids induce mesenchymal stem cells to increase secretion of angiogenic mediators. J Cell Physiol. 2012;227(9):3225-3233.

48. Tian H, Lu Y, Shah SP, Hong S. 14S,21R-dihydroxydocosahexaenoic acid remedies impaired healing and mesenchymal stem cell functions in diabetic wounds. J Biol Chem. 2011;286(6):4443-4453.

49. Turinetto V, Vitale E, Giachino C. Senescence in Human Mesenchymal Stem Cells: Functional Changes and Implications in Stem Cell-Based Therapy. Int J Mol Sci. 2016;17(7):E1164.

50. Chatgilialoglu A, Rossi M, Alviano F, et al. Restored in vivo-like membrane lipidomics positively influence in vitro features of cultured mesenchymal stromal/stem cells derived from human placenta. Stem Cell Res Ther. 2017;8(1):31.

51. Nigam e, Lieberthal W. Acute renal failure. III. The role of growth factors in the process of renal regeneration and repair. Am J Physiol Renal Physiol. 2000;279(1):3-11.

52. Razban V, Lotfi AS, Soleimani M, et al. HIF-1 $\alpha$ Overexpression Induces Angiogenesis in Mesenchymal Stem Cells. Biores Open Access. 2012;1(4):174-183.

53. Dai C, Liu Y. Hepatocyte growth factor antagonizes the profibrotic action of TGF-beta1 in mesangial cells by stabilizing Smad transcriptional corepressor TGIF. J Am Soc Nephrol. 2004;15(6):1402-1412.

54. Lan YW, Choo KB, Chen CM, et al. Hypoxia-preconditioned mesenchymal stem cells attenuate bleomycin-induced pulmonary fibrosis. Stem Cell Res Ther. 2015;6:97.

55. Hu X, Sp Y, Fraser JL, et al. Transplantation of hypoxia-preconditioned mesenchymal stem cells improves infarcted heart function via enhanced survival of implanted cells and angiogenesis. JThorac Cardiovasc Surg. 2008;135(4):799-808.

56. Yu J, Liu XL, Cheng QG, et al. G-CSF and hypoxic conditioning improve the proliferation, neural differentiation, and migration of canine bone marrow mesenchymal stem cells. Exp Ther Med. 2016;12(3):1822-1828.
57. Lu H, Wu X, Wang Z, et al. Erythropoietin-activated mesenchymal stem cells promote healing ulcers by improving microenvironment. J Surg Res. 2016;205(2):464-473.

58. Kwon YW, Heo SC, Jeong GO, et al. Tumor necrosis factor- $\alpha$-activated mesenchymal stem cells promote endothelial progenitor cell homing and angiogenesis. Biochim Biophys Acta. 2013;1832 (12):2136-2144.

59. Lu Z, Wang G, Dunstan CR, et al. Activation and promotion of adipose stem cells by tumor necrosis factor- $\alpha$ preconditioning for bone regeneration. J Cell Physiol. 2013;228(8):1737-1744.

60. Wang J, Liao L, Wang S, Tan J. Cell therapy with autologous mesenchymal stem cells-how the disease process impacts clinical considerations. Cytotherapy. 2013;15(8):893-904.

61. Wang W, Itaka K, Ohba S, et al. 3D spheroid culture system on micropatterned substrates for improved differentiation efficiency of multipotent mesenchymal stem cells. Biomaterials. 2009;30(14):2705-2715.

62. Frith JE, Thomson B, Genever PG. Dynamic three-dimensional culture methods enhance mesenchymal stem cell properties and increase therapeutic potential. Tissue Eng Part C Methods. 2010;16(4):735-749.

63. Jackson MV, Krasnodembskaya AD. Analysis of Mitochondrial Transfer in Direct Co-cultures of Human Monocyte-derived Macrophages (MDM) and Mesenchymal Stem Cells (MSC). Bio Protoc. 2017;7(9):pii: e2255.

64. Perico L, Morigi M, Rota C, et al. Human mesenchymal stromal cells transplanted into mice stimulate renal tubular cells and enhance mitochondrial function. Nat Commun. 2017;8(1):983.

65. Sanchez V, Villalba N, Fiore L, et al. Characterization of Tunneling Nanotubes in Wharton's jelly Mesenchymal Stem Cells. An Intercellular Exchange of Components between Neighboring Cells. Stem Cell Rev. 2017;13(4):491-498.

66. Trounson A, McDonald C. Stem Cell Therapies in Clinical Trials: Progress and Challenges. Cell Stem Cell. 2015;17(1):11-22.

67. Schulz TC, Young HY, Agulnick AD, et al. A scalable system for production of functional pancreatic progenitors from human embryonic stem cells. PLoS One. 2012;7(5):e37004.

68. Schwartz SD, Hubschman JP, Heilwell G, et al. Embryonic stem cell trials for macular degeneration: a preliminary report. Lancet. 2012;379(9817):713-720.

69. Schwartz SD, Regillo CD, Lam BL, et al. Human embryonic stem cell-derived retinal pigment epithelium in patients with age-related macular degeneration and Stargardt's macular dystrophy: follow-up of two open-label phase 1/2 studies. Lancet. 2015;385(9967):509-516.

70. Grealish S, Diguet E, Kirkeby A, et al. Human ESC-derived dopamine neurons show similar preclinical efficacy and potency to fetal neurons when grafted in a rat model of Parkinson's disease. Cell Stem Cell. 2014;15(5):653-665.

71. ClinicalTrials.gov. [Home page on the internet]. http://www.clinicaltrials.gov. Accessed March 5, 2018.
Stem Cells and Cloning: Advances and Applications

\section{Publish your work in this journal}

Stem Cells and Cloning: Advances and Applications is an international peer-reviewed, open access journal. Areas of interest in stem cell research include: Embryonic cell stems; Adult stem cells; Blastocysts; Cordblood stem cells; Stem cell transformation and culture; Therapeutic cloning; Umbilical cord blood and bone marrow cells; Laboratory,

\section{Dovepress}

animal and human therapeutic studies; Philosophical and ethical issues related to stem cell research. This journal is indexed on CAS. The manuscript management system is completely online and includes a quick and fair peer-review system. Visit http://www.dovepress.com/ testimonials.php to read real quotes from published authors. 